\title{
Impact of Tax Evasion Among tax Payers of Bale Robe Town Administration, Ethiopia
}

\author{
Birhanu Hailu \& Tarik Kechema \\ Department of Accounting and Finance, Collage of Business and Economics, \\ Madda Walabu University, Ethiopia \\ Email: tarikacfn@gmail.com
}

\begin{abstract}
The main purpose of this study was to investigate the impact of tax evasion among tax payers of payers Robe town administration. To attain the intended objective the study used quantitative research method and logit method for the econometrics model. And to collect the necessary data from the respective respondents questionnaire was distributed and collected from 346 respondents. For the data analysis SPSS version 20.0 was used. The finding of this study revealed that; tax knowledge, efficiency of tax authority, equity, and tax audit are found to be significant factors that could affect the tax evasion perception of tax payers.
\end{abstract}

Keywords: taxpayers' perception, tax evasion, Logit method

\section{Introduction}

Taxation has gained importance not only as a tool for raising revenue to meet the administrative costs of governance as well as for the provision of public services but it also serves as a tool available to planners, policy makers and implementers aiming to regulate the economy in order to bring about desired economic development (Palil 2010). That is why citizens are expected to discharge their civic responsibility by paying their taxes as these contribute to the development and administration of the society at large (Murkur, 2001). However, significant taxes to be collected find their way out of the economy through tax evasion and due to the fact that people do not like to pay taxes and that tax authorities have difficulty imposing and collecting taxes (Fagbemi \& Noah 2010). In fact, tax evasion is a phenomenon present in all societies (Uadiale, Fagbemi, \& Ogunleye, 2010).

It is found to be threatening to tax authorities, especially in developing countries. Recently, there is drastic reduction in states budget all over the world because of practice of tax evasion by economic agents. The value of tax evasion in the world over all is in excess of US\$3.1 trillion approximately 5.1\% of global GDP (Muhrtala \& Ogundeji, 2013). Moreover, Murphy (2011); Ching, (2013), showed that the total size of shadow economy on total GDP, by region, South America (36.8\%) is placed at the top of the list, followed by Africa (34.8\%), Europe $(20.5 \%)$, Asia (17.7\%), Oceania (14.1\%) and North America (10.8\%). As per Tilahun and Yidersal (2014), Ethiopia has a tax to GDP of $12.2 \%$ which is lower than other African countries of Kenya $17.7 \%$, zamibia $17 \%$, Malawi $15.6 \%$ and Rwanda $14.1 \%$. The country's tax mobilization is also the lowest among most African countries. Beside, Empirical evidences witnessed that the Ethiopian tax-to-GDP ratio is low. As per OECD.org (2017) report it has been mentioned in the second Growth and Transformation Plan (GTPII), the share of tax revenue amounted to only 13.3 percent of the GDP, which is far below the average tax-to-GDP ratio for Sub-Saharan countries. From this, it follows that the country has a room to increase its domestic revenues which is exactly what the government has done by applying a business profit tax rate revision 
over the last months. The achievement of this intention will be unimaginable to attain without understanding perception of taxpayers towards tax evasion. Hence, this study was intended to investigate perception of tax evasion among tax payers of Robe town administration.

\section{Literature Review}

Tax evasion is a word used to describe efforts of individuals and corporate entities towards dishonest reduction of tax liabilities. It has been described by Alm \& Martinez-Vazquez (2001) as a thoughtful and eagerly practices of not unveiling comprehensive taxable income in order to reimburse lesser tax. Sardjono (2013) Stated that the willingness of tax payers to pay tax depends on knowledge and understanding of tax rules and good perception of the effectiveness of the taxation system. And at the same period Fjeldstad et.al ( 2013) stated that compliance with tax depend on the taxpayers knowledge that they cannot evade taxes and that the more individuals are satisfied with the public services provides by governments the more the likelihood of tax compliance. They further stated that tax payer' intentions for compliance will increase if they perceive the government utilizing revenue generated form tax, otherwise they will become less committed towards compliance. While the findings of (Kamil and Nurlis, 2015) stated that taxpayer compliance is depends on tax awareness and tax penalties. Their finding showed that more effective application of tax penalties the higher the tax compliance. They further argued that knowledge hand awareness of taxpayers the more the likely to avoid tax liabilities.

Beside, Loo, Mckerchar and Hansford (2009) indicate that the ability of taxpayer's in complying tax by reporting taxable income, claim relief, rebates and compute tax liability correctly can be determined by the sufficiency of taxpayer's knowledge toward tax policy. Mukasa (2011) agreed that tax knowledge has a significant positive relationship with tax compliance behavior. As the result from their research, higher tax knowledge is expected to lead to higher compliance rates and lower tax knowledge lead to lower tax compliance rate in adverse. The survey among small and medium registered taxpayers operating in Kampala central division found that low tax knowledge is one of the significant factors which contributed to less compliance. This is because lack of knowledge of tax law coupled with inadequacy of taxation books in layman terms to guide them which will contribute to unintentional tax non-compliance.

Mughal \& Akram (2012) have found a significant relationship between tax evasion and tax system in Pakistan. In other studies by Lutfi (2009) and Fakile \& Uwuigbe (2013), tax system has a negative relationship with tax evasion. Corruption is an act by taxpayer to pay something to somebody in order to relief the taxpayer from taking part in paying taxes or evading taxes. Akinyomi \& Okpala (2013) for example, assess the factors influencing tax evasion and avoidance in Nigeria through a survey and found that the level of corruption has a positive relationship with tax evasion. However, Tijani \& Mathias (2013) when studying expert viewpoint of tax evasion in Nigeria, concluded that a negative relationship exist between corruption and tax evasion. Beside, Literature has identifies reason for the different perceptions towards tax avoidance. Several reason were identified by literature on different perceptions among which; willingness of taxpayers, understanding the tax rules and utilization of tax revenues.

Agyemang badu(2015) perform study on assessment of citizen's attitudes towards tax evasion and non-compliance, in Ghana. The study revealed that whereas tax evasion on total or a huge portion of revenue is measured offensive, minor measure of tax evasion (between 9 to $12 \%$ on earnings) is estimated as allowable activity. Minor measure of evasion is well-thought-out as 
more suitable than entirely other wrongdoings counted in the study, plus thefts of stationeries in the office. Further discoveries showed that some individuals are convinced that tax evasion is mutual among their peers is absolutely linked to their reception of tax evasion, and as such, tax evasion is seen as a additional satisfactory action by less revenue sets, and by labor-intensive employees rather than directors and supervisors. according to Manik Asri in Rahayu (2010), the taxpayer is recognized as having awareness if they: (1) recognize the existence of the tax laws and regulations, (2) knowing that the tax function is to finance state, (3) understand that the task taxes must be paid in accordance with the applicable rules, (4) calculate, pay, and report their taxes voluntarily and accurately.

Study conducted by Suresh Vadde and SrinivasGundarapu (2010), on major factors that influence attitudes of rental taxpayers and their compliance behavior with tax system in Mekele city administration and their study revealed that there were some dishonest rental tax payers. Even there are some individually who entirely don't report their taxable income to the concerned body. In addition to the above, the study also disclosed that with the exception of minority of the rental tax payers who hold certificate and diploma, majority of them were with an educational background of elementary and high school completed. Hence, it can be concluded that rental tax payers lack knowledge of easily understanding the laws and regulations of the tax system and how their taxable income is computed. Also the authors concluded that; still many respondents are not attending or participating in the tax training session. Also, Wollela A Yesegat and HelgeFjeldstad, (2011) jointly conducted study on tax payers views of business taxation in Ethiopia. The objectives of their study were to assess business peoples' views of paying taxes in Ethiopia and to identify (perceived) difficulties with the tax system and priorities for tax reform. Hence the result showed that the main reasons for tax noncompliance were; lack of predictability in the tax system forces taxpayers to reduce their current tax liability, difficult to compete with businesses that import goods at manipulated custom duties, It is those who are not paying taxes that are quickly growing, so why should I comply, discrimination by the tax administration forces honest taxpayers to evade taxes;

While Nuguss et.al, (2014) conducted study on the consequences of tax assessment on tax collection of category ' $c$ ' taxpayers in Ethiopia: a case study in Mekelle city, Tigray. The study found that unless good service delivery is provided, tax related laws are enforced and implemented, effective awareness creation is done and fair tax assessment is conducted, there may not be efficient and effective tax collection. Even though efficient tax assessment and collection cannot be made overnight, it is up to tax administrators to ensure sufficient tax revenue. Multiple approaches are needed to enhance tax collection efficiency. No single approach is likely to fully and effectively address the tax collection efficiency of category ' $\mathrm{C}$ '. Since it has multiple causes of tax related problems, the category " $C$ " tax payers needs more attention.

The study made by Yohanne and Zerihun(2013) on identifying the gaps and problems that exist between the Dire Dawa business community and the tax authority results show that most of the taxpayers, especially those in the category ' $\mathrm{C}$ ', do not exactly know how the tax is assessed or calculated and the procedures in the tax assessment and computations are not objectively understood by most of the taxpayers. The finding also revealed that; over taxation as result of over estimation of daily/annual income, Nontransparent, non-participatory standard assessment by the authority on category "C taxpayers", Lack of fairness or equity of taxation among similar businesses of category "C taxpayers" Poor tax laws enforcement especially for VAT and large 
number of tax defaulters, Poor communication and understanding between the tax authority and taxpayers, Weakness in tax collection and unsatisfactory service delivery of tax authority.

As per the finding of Mukhlis, et.al (2015), there is a positive and significant relationship between tax education on tax knowledge and tax compliance on Handicraft SMEs Sectors in Indonesia support the above statement and note that there was a positive significant relationship between taxpayer's tax knowledge and tax compliance. The taxpayers who have equipped with the sufficient tax knowledge are able to access their tax liability correctly ad file tax return forms on time. Taxpayer cannot be expected to submit complete, proper tax returns accurately unless they have sufficient knowledge to understand the system. However, Kasipillai, Aripin, and Amran (2013), oppose the argument on positive correlation between tax knowledge and tax compliance has opposed by some of the studies. They found that there is a significant negative relationship between tax knowledge and compliance behavior. They claim that the increasing knowledge of tax such as audit process and tax regulations expose taxpayers the opportunity to evade tax. In other word, taxpayer who has higher level of tax knowledge is well-know about the loophole in tax regulation and system know the legal way to reduce or even avoid tax. From their research, they found that tax compliance to be higher for taxpayers who were less well educated and older.

Under the self-assessment tax system, one of the objectives of the taxing authority is to achieve voluntary tax compliance by the majority of the taxpayers (Kasipillai et al., 2011). But, it is common that a large proportion of taxpayers may be unable to complete their own tax returns due to lack of knowledge and understanding of tax laws and regulations. It was also found that there was a strong positive relationship between tax knowledge and the level of voluntary tax compliance (Kasipillai, Mustafa, Noraza, \& Munusamy, 2009). Hai and See (2011) and Clotfelter, 2012) found that the high tax rate results in high tax noncompliance. Spicer \& Becker (2013) also argue that those taxpayers who are aware that their tax rate is higher than average tax rate paid by other have higher tendency of tax evasion and tax noncompliance. By the same token, those tax payers who perceive that paying tax rate can overshadow their high tax rate payment through tax evasion. They also claimed that decreasing tax rates is not the only policy that has the potential to encourage tax compliance and discourage tax evasion. Nevertheless, the tax rate is an important factor in influencing tax compliance attitude even if the exact impact is still controversial and unsolved. Beside, Tax audits, frequency of audit and prior audit experience have been ambiguously discussed in relation to tax compliance. Some studies found out that audits have a positive relationship with tax evasion (Tadesse\& Goitom, 2014). These findings recommended that tax audits can play an important role in tax compliance. Frequency of audits and the carefulness of tax audits could encourage taxpayers to become more careful computing and submitting their tax returns. Conversely, taxpayers who have never been audited might be trying understating their income and over stating their deductions (Palil, 2010).

A study by Beron, Tauchen and Witte, (1988) and Tilahun and Yidersal (2014) argue that audits did not significantly relate with tax compliance; which indicated that previous studies have found controversial results about the association between tax audit and tax compliance.

If tax payers perceive that the government is wisely spending the tax revenue for public goods and services, it is expected that voluntary tax compliance will enhance. But, if taxpayers believe that the government is spending tax revenue unwisely on unnecessary things then taxpayers will feel be unfaithful to and attempt to avoid taxes (Palil \& Mustapha, 2011). Also, Palil (2010), simplicity of tax system has one of an imperative factor that determines tax compliance 
behavior of tax payers.

\section{Research Method}

In this research, the authors used primary data and for the data collection structured questionnaires was made. The questionnaires were adopted and developed with some modification from previous similar studies such as MuleyeT(2016),Belachew et.al,(2015) and Alis and Brooke(2017) were used and Closed ended questionnaires were prepared in the form of five Likert-Scale, Where; Strongly Agree $[\mathrm{SA}]=5$; Agree $[\mathrm{A}]=4$; Neutral $[\mathrm{N}]=3$, Disagree $[D]=2$; and Strongly Disagree $[S D]=1$; for continuous variables. The use of Likert scale is to make it easier for understanding, reduce confusion in reading and answering the questionnaire by respondents. The target population of this study were all business income tax payers of Robe Town Administration; South East Ethiopia. According to Robe town Revenue Authority Report of 2018, they are estimated to be 4,160 tax payers consists of 310 category "A", tax payers 262 category " $\mathrm{C}$ " and 3,588 category ' $\mathrm{C}$ ' business income tax payers are registered and taken as target population of this study by the authors.

The researcher considered three categories of taxpayers as clusters and selected sample out of each three clusters using simple random sampling because in scenario of selecting sample from clusters "the groups are termed clusters in this form of sampling and can be based on any naturally occurring grouping" (Kothari 2004).

To determine the sample size from total taxpayers in the town, mathematical formula of Yimane $\mathrm{T}$ (1967) is used by taking in to account the total population, the sampling error and the level of reliability. It is assumed that the sample would have $95 \%$ reliability about population and a sampling error will be $5 \%$. This simplest formula is given as follows:

$n=\frac{N}{1+(0.5)^{2} \times N}$

Where; $\mathrm{N}=$ study population, $\mathrm{n}=$ sample size and $\mathrm{e}=$ error margin

Accordingly, sample was first determined from total target population by formula of Yimane $\mathrm{T}$ (1967) as $365=4,160 / 1+(0.05) 2 * 4,160$ then, to randomly select sample from three categories by the following formula of [29] was also used by the author and showed in the following table 1. This is: $n h=(N h / N s) * n$ Where, $\mathrm{nh}=$ sample size from each site, $\mathrm{Nh}=$ total population, Ns $=$ target population and $\mathrm{n}=$ sample size from target population.

Table 1. Determination of sample size from each category by applying formula

\begin{tabular}{|l|l|l|l|}
\hline Sampling Cluster & $\begin{array}{l}\text { Population of each } \\
\text { Category }\end{array}$ & $\begin{array}{l}\text { Sample Size } \\
\text { calculation }\end{array}$ & Sample size \\
\hline Category "A" & 310 & $(310 / 4,160) * 365$ & 27 \\
\hline Category "B" & 262 & $(262 / 4,160) * 365$ & 23 \\
\hline Category "C" & 3,588 & $(3,588 / 4,160) * 365$ & 315 \\
\hline Total & 4,160 & $(4,160 / 4,160) * 365$ & 365 \\
\hline
\end{tabular}

Source: Personal survey

Tax evasion perception is discrete random variable and dummy in nature that could be measured through logit or binary logistic regression model. Accordingly, the researchers has developed the model by driving logit function from odds ratio and incorporated eight explanatory variables which disclosed as follows: 
TEP=F(TKN, TR, TA, ETA, PEQ, IL, PI, TP, CoC). Where; TEP, Is tax evasion perception, TKN is Tax knowledge, TR is Tax rate, TA is tax audit, ETA is efficiency of tax authority, PEQ is perception on equity, IL is income level, PI is peer influence, TP is tax penalty and CoC is compliance cost. Hence, the researchers have developed the logistic regression model to achieve the objective of this study. Logistic regression is one of binary choice models (or dichotomous models), which is designed to model the 'choice' between two discrete alternatives. This model essentially describes the likelihood of observing success event $(\boldsymbol{Y} \boldsymbol{i}=\mathbf{1})$ is directly depends on observed explanatory variables which are exogenous to the model. Tax evasion as a binary choice: to evade or not. Yet, a recent experimental study by Alm et al. (2017) stressed the necessity to analyze tax evasion as a two-stage choice (see also Benjamini and Maital, 1985; Gordon, 1989): the binary decision to either evade or not, and the choice of the amount to evade. Since, dependent variable, (i.e., tax evasion perception) is a binary outcome (dichotomous) variable and treated as qualitative data and the researcher assumes one (1) for evading, otherwise zero (0). For this data, logistic regression is appropriate model to measure how explanatory variables (factors influencing tax evasion perception) affect individual's likelihood of evade or not evade. The Logit function can be derived from odds rations:

\section{$\log ($ O d d s ratio $)=\log ($ S uccess $/$ F a il ure $)$ $=\log (\boldsymbol{y} i=\mathbf{1} / \boldsymbol{y} i=\mathbf{0})=\beta \mathbf{0}+\boldsymbol{x} \boldsymbol{i}^{\prime} \boldsymbol{\beta}$}

Where, $\boldsymbol{y} \boldsymbol{i}=\mathbf{1}$ represents an individual " $\mathbf{i}$ " is being not to evade (success), $\boldsymbol{y} \boldsymbol{i}=\mathbf{0}$ represents an individual " $\mathbf{i}$ " is being to evade (failure), $\boldsymbol{x} \boldsymbol{i}$ is column vector of explanatory variables (ED, TKN, TR, TA, ETA, PEQ, IL, and PI, $\boldsymbol{\beta}$ is column vector of parameters (coefficients) to be estimated and $\boldsymbol{\beta} \mathbf{0}$ is the intercept term.

A number of statistics were used to assess how the model was fitting the data. Hence, for the purpose of this study the omnibus test statistic was used to assess whether there was a linear relationship between the probability of success or failure and the independent variables. In the omnibus test statistic p-value less than 0.05 implied that the logistic regression could be used to model the data. So, as per omnibus test result indicated in table 2 below, p-value is 0.000 . Besides, Enter methods were used for fitting binary logistic regression to establish the variables that are associated with tax evasion perception. Therefore, logistic regression is fitted to model the data.

Table 2. Omnibus Tests of Model Coefficients

\begin{tabular}{|c|l|l|l|l|}
\hline \multicolumn{6}{|l|}{ Omnibus Tests of Model Coefficients } \\
\hline Model & & Chi-square & Df & Sig. \\
\hline \multirow{3}{*}{ Enter } & Step & 126.057 & 9 & .000 \\
\cline { 2 - 5 } & Block & 126.057 & 9 & .000 \\
\cline { 2 - 5 } & Model & 126.057 & 9 & .000 \\
\hline
\end{tabular}

Besides, the Wald statistic was used to assess the importance on individual independent variables in predicting the probability of success or failure of evasion. A coefficient with a Wald statistic p- less than 0.05 implies that the variable is important in the model and those variables with p-values greater than 0.05 were considered to be unimportant (Hosmer and Lemeshow, 2000) and which is given in table 3 below. 
Table 3. Variables in the Equation

\begin{tabular}{|l|l|l|l|l|l|l|}
\hline & B & S.E. & Wald & df & Sig. & Exp(B) \\
\hline Constant & -.0804 & .0116 & 47.733 & 1 & .000 & 1.0448 \\
\hline
\end{tabular}

\section{Findings and Discussions}

Table 4. Binary Logistic Regression Result

\begin{tabular}{|c|c|c|c|c|c|c|}
\hline & $\mathrm{B}$ & S.E. & Wald & Df & Sig. & $\operatorname{Exp}(B)$ \\
\hline Taxknowledge & .0134 & .0301 & 6.146 & 1 & $.000 *$ & 1.705 \\
\hline Taxrate & .272 & .167 & 2.659 & 1 & .130 & .313 \\
\hline Taxaudit & .096 & .0286 & 3.112 & 1 & $.038^{*}$ & 1.100 \\
\hline Efficiency of taxauthority & .0354 & .0221 & 5.583 & 1 & $.000^{*}$ & 1.425 \\
\hline Equity & -.0495 & .0299 & 4.733 & 1 & $.000 *$ & .610 \\
\hline Income level & -.0288 & .0174 & 3.745 & 1 & .054 & .630 \\
\hline Peer influence & -.266 & .185 & 2.069 & 1 & .150 & .767 \\
\hline Tax penalty & .052 & .052 & 6.002 & 1 & .110 & 1.053 \\
\hline Compliance cost & -.288 & .185 & 2.432 & 1 & .119 & .750 \\
\hline Constant & -1.434 & 1.559 & .846 & 1 & .358 & .238 \\
\hline
\end{tabular}

Source: Own computation, 2019

Wald statistics and significance level revealed that; tax knowledge, tax audit, efficiency of tax authority, and equity were found to be significance in influencing the perception of tax evasion of tax payers; which is indicated by p-values of less than 0.05 .

As per the result of the study showed; tax knowledge is among the variables that highly determine the tax evasion perception of tax payers which is at $5 \%$ significance level, $p$-vale of 0.000 . Since having good understanding of the benefit of tax contribution towards the government mandatory; the knowledge hand awareness of tax payers the more the likely to avoid tax liabilities. Also low tax knowledge is one of the significant factors which contributed to less compliance because lack of knowledge of tax law coupled with inadequacy of taxation books in layman terms to guide them which will contribute to unintentional tax non-compliance. Besides, Loo, Mckerchar and Hansford (2009) indicate that the ability of taxpayer's in complying tax by reporting taxable income, claim relief, rebates and compute tax liability correctly can be determined by the sufficiency of taxpayer's knowledge toward tax policy. This finding was supported by the findings of Fjeldstad et.al (2013), (Kamil and Nurlis, 2015),Mukasa (2011), Jatmiko (2006). Equity is the second variable that highly influences tax evasion perception of tax payers with p-value of 0.000 . Equity/fairness in this study is significant and negatively influences the tax evasion perception of tax payers. This finding implies that lack of fairness/equity of by tax authority especially at the time of assessment for those category ' $\mathrm{C}$ ' tax payers directly lead them to tax evasion. Which is in line with the findings of Chain et.al, (2015), Jackson \&Milliron (1986), Yohanne and Zerihun(2013); Lack of fairness or equity of taxation among similar businesses of category "C taxpayers" Poor tax laws enforcement especially for VAT and large number of tax defaulters, Poor communication and 
understanding between the tax authority and taxpayers, Weakness in tax collection and unsatisfactory service delivery of tax authority. The other factors that influence tax evasion perception of tax payers were the efficiency of tax authority with p-value of 0.000 at $5 \%$ significance level. This finding implies that the tax authorities were not diligent in awareness creation of the importance of paying tax towards the government, i.e they were too late to create awareness of the importance of tax contribution towards the economy. Also tax audit is factors that affect tax evasion perception of tax payers with $p$-value of 0.038 . Which support the findings of Palil, (2010).) Stated that frequency of audits and the carefulness of tax audits could encourage tax payers to become more careful computing and submitting their tax returns. Conversely, taxpayers who have never been audited might be trying to understand their income and over stating their deductions.

\section{Conclusion}

Since tax is the main sources of government revenue and hot as current issues, beside tax evasion is a series problem that hindered to attain the objective of revenue authority in tax collection. Hence, investigation on the area is unquestionable; so the study identified the following core findings; Majority of tax payers doesn't know the benefit of tax contribution towards the government even though they know the payment is compulsory. This is due to lack of awareness/knowledge of tax payment which leads to less compliance with the tax law, beside there was lack of fairness/equity of tax authority at the time of tax collection among similar business through assessment and has corrupt employees. Also the tax authority is not efficient in creating awareness and collecting the intended amount from tax.

Therefore, the tax authority has to do on creating awareness concerning the benefit of paying taxes. Especially as the payment of tax is compulsory they perceive as if the return from tax doesn't reach them by any means. Also The tax authority has to be fair in assessing similar business by following the ability to pay principle and punish their corrupt employees those who are involved on assessment and enforce as the tax payers has to audited their business; this enables the tax payers to disclose the accurate tax return.

\section{References}

Alm, J., Torgler, B., \& Martinez- V. (2006). Culture differences and tax morale in United States and Europe. J. Econ. Psychol, 27, 224-246.

Belete, B., Abebe, A., Galgalo, G., Frihywote, A., \& Mahlet, G. (2015). Category “C'” business tax payers' perception on tax evasion: The Case of Debre Berhan City Administration.

Chain, B., Fong, L.S, \& San, P.W. (2015). Factors that influence tax evasion among individual taxpayers (employment) in Malaysia. Journal of European Academic Research, 3(5).

Chiumya, C. (2006).Counteracting tax evasion In Malawi: An analysis of the methods and a quest for improvement. international graduate school of social sciences. Online at http://mpra.ub.unimuenchen. de/9892/

Creswell, J.W. (2009). Research design: Qualitative, quantitative, and mixed methods approaches, $3 r d$ ed. New York: Sage Publications.

Fagbemi, O. T., \& Noah, O. A. (2010). The ethics of tax evasion: Perceptual evidence from Nigeria. European Journal of Social Sciences, 17(3).

FDRE. (2016). Income Tax Regulation No.979/2016, Federal Negarit Gazeta, Addis Ababa, 
Ethiopia.

Kasipillai, J., Aripin, N., \& Amran, N. (2013). The influence of education on tax avoidance and tax evasion. eJournal of Tax Research, [online] 1(2). Available at: http://www.austlii.edu.au/au/journals/eJTR/2003/7.html

Kothari, C.R. (2004). Research methodology; methods and techniques 2nd ed. New Delhi: New Age International.

Muhrtala, O.T., \& Ogundeji, M. (2013). Professionals' perspective of tax evasion: Some evidence from Nigeria Universal. Journal of Accounting and Finance, 1(2), 35-41, DOI: 10.13189/ujaf.2013.010201

Muleye, T. (2016). Taxpayers' perception on the seriousness of tax evasion in Dessie Town Administration, Ethiopia. Research Journal of Finance and Accounting, 7(19).

Mukur, G. A. (2001). Design of tax systems and corruption. Conference Paper on "Fighting Corruption: Common Challenges and Shared Experiences". Konard Adenauer Stiftung, and the Institute of International Affairs (SIIA), Singapore.

Palil R., M. (2010). Taxpayers knowledge: A descriptive evidence on demographic factors in Malaysia. Jurnal Akuntansi \& Keuangan, 7(1).

Pashev, K. (2005). Tax compliance of small business in transition economies: Lessons from Bulgaria. Working paper 05-10. Andrew Young School of Policy Studies. Antlanta Georgia.

Richardson, G. (2008). The relationship between culture and tax evasion across countries: Additional evidence and extensions. Journal of International Accounting, Auditing and Taxation, 17, 67-78.

Tilahun, A., \& Yidersal, D. (2014). Determinants of tax compliance behavior in Ethiopia: The case of Bahir Dar City tax payers. Journal of Economics and Sustainable Development, 5(15).

Uadiale, M. O., Fagbemi, O. T., \& Ogunleye, O. J. (2010). An empirical study of the relationship between culture and personal income tax evasion in Nigeria. European Journal of Economics, Finance and Administrative Sciences, 20.

Yamane, T. (1967). Statistics: An introductory analysis. 2nd edition.

\section{Copyrights}

Copyright for this article is retained by the author(s), with first publication rights granted to the journal.

This is an open-access article distributed under the terms and conditions of the Creative Commons Attribution license (http://creativecommons.org/licenses/by/4.0/) 